Revista de Dialectología y Tradiciones Populares, vol. LXVI, n. ${ }^{\circ}$, pp. 197-228, enero-junio 2011, ISSN: 0034-7981, eISSN: 1988-8457, doi: $10.3989 /$ rdtp. 2011.08

\title{
La fortuna del mueble español en el mercado de arte como reflejo de su valoración social
}

\section{The fate of Spanish furniture on the art market as reflection of its social valuation}

\author{
Sonsoles Caruana Moyano \\ TDA Tasaciones de Arte
}

"Todo necio confunde valor y precio"

Antonio Machado

\section{RESUMEN}

El mueble no comenzó a ser tratado en España como objeto de estudio científico —-salvo honrosas excepciones- hasta la década de 1970. En ese momento irrumpe además en el panorama nacional una nueva forma de venta de arte, al margen de anticuarios y marchantes: las subastas, nacidas dos siglos atrás en Inglaterra. Así, lo académico y lo comercial se aúnan: publicaciones rigurosas, estudios concienzudos y catálogos de mobiliario, favorecen la aparición de nuevas piezas en muchas ocasiones a través del canal del mercado del arte, que, a su vez, nutren dichos estudios. Se aprende a valorar, en el sentido más amplio del término, el mobiliario. Lo que lleva a su conservación, su divulgación y también, por qué no, a establecer su valor pecuniario.

Palabras clave: Muebles, Mercado de arte, Subastas, España.

\section{SUMMARY}

In Spain furniture did not begin to be dealt with as material for scholarly research -with notable exceptions - until the 1970s. Likewise at that time a new form of art sales appeared on the national scene in addition to antique and art dealers: auctions, invented in England 200 years earlier. Thus the scholarly and the commercial came together: rigorous publications, thorough studies and catalogues of furniture which encouraged the appearance of new pieces, in many instances via the channel of the art market- that in turn nourished serious studies. Consequently furniture began to be valued in the broadest sense of the term, leading to its conservation, its dissemination and fixing its monetary worth.

Key words: Furniture, Art Market, Auctions, Spain. 


\section{VALORACIÓN TRADICIONAL DEL MUEBLE EN ESPAÑA}

La celebración de la exposición "Mueble Español. Estrado y Dormitorio", hace ya veinte años, puede ser considerada — a nuestro juicio- reflejo de la culminación y del punto de partida que supusieron para la historiografía del mueble en España aquellos años. Culminación, por ser consecuencia materializada de un progresivo interés por abordar el estudio del mobiliario desde una óptica estrictamente científica, algo que se venía constatando en nuestro país de una manera más plausible desde los años 70, tal y como repasa en la introducción a su catálogo Gabriel Moya (1990: 11-22). A partir de entonces una nueva generación de investigadores abordará desde ese mismo interés el estudio del mobiliario, si bien desde perspectivas muy diferentes ya que, por su propia naturaleza, el mueble es susceptible de ser estudiado desde muy diversos puntos de vista; ya sea atendiendo a su calidad artística, a su carácter etnográfico, a su diseño, o a factores colaterales como son su conservación y restauración. De este modo, se ha multiplicado en este tiempo la aparición de artículos y monografías sobre el mueble español, tanto divulgativas como científicas. De forma paralela se ha incrementado la oferta de cursos, seminarios, incluso exposiciones que parecen ser reflejo de un creciente interés por las artes decorativas en general y por el mueble en particular, por encima de modas y otras coyunturas. Es lógico, habida cuenta de que en nuestro país ha sido un campo tradicionalmente tratado como de "segundo orden" en lo que a la investigación se refiere, prácticamente ignorado en los programas universitarios. Además del vacío hasta entonces constatado, este campo se ha consolidado en los últimos años como objeto de salidas laborales interesantes, precisamente por su vinculación con el mercado de arte.

\section{Valores del mueble. Consideraciones generales}

Los muebles son objetos necesarios de los que el ser humano se ha servido a lo largo de la historia. Asegurados comida y abrigo se busca la comodidad; y de una preocupación estética y un afán diferenciador, en ocasiones, derivan en objetos artísticos e incluso, algunos, llegando a tener la consideración de obras de arte. Supone por tanto el mobiliario un factor para conocer el grado de desarrollo alcanzado por una sociedad, así como de aspectos dispares como su capacidad tecnológica y las costumbres y relaciones sociales establecidas.

Es sabido que diferentes etiquetas, protocolos o modos de comportamiento tienen en los muebles uno de sus principales accesorios y símbolos (Aguiló 
1993: 15-24). Susceptibles a las modas, se hacen eco de los cambios de gusto de una manera más rápida y directa que otras artes. Precisamente ese carácter de inmediatez es el que también provoca que sea lo primero que se recicle, deseche o rehaga a la hora de adaptarse a nuevas modas y corrientes, de ahí junto a su esencia eminentemente funcional la dificultad de que los más antiguos (y los que no lo son tanto) lleguen a nuestros días intactos y raramente en su contexto, lo que produce dificultades añadidas a su estudio.

Que el mueble en sus formas y materiales no ha sido cuestión baladí se vislumbra en el hecho de que destacados teóricos hayan reflejado la preocupación estética y formal que han sentido por el tema en sus escritos, presentando aquellos enseres como manifestación material del estatus y del poder económico; aún es más, como reflejo de aquello intangible ligado al individuo, intentando hacerse eco, y engrandeciendo, las virtudes y cualidades de su dueño.

Han sido objeto de cambio, de regalos diplomáticos; tratados inevitablemente como mercancías, variando a lo largo de la historia el modo de adquisición, ya fuera a través de encargos mediante el mecenazgo de monarquías, familias de abolengo o de la propia Iglesia; por venta directa en talleres de artistas y artesanos, en ferias periódicas o, más adelante, con la aparición de los marchantes, tiendas de anticuarios y galerías.

Las obras de arte — los objetos artísticos y las antigüedades - son pues un hecho plural, donde convergen diferentes dimensiones, una plástica o estética, sin duda la más trascendente, pero evidentemente poseen una dimensión social y, por supuesto, también económica. Sin embargo en los ámbitos académicos ligados a la historia del arte se ha obviado repetidamente este aspecto, nos hacemos eco de una acertada reflexión:

\footnotetext{
parece como si ambos conceptos, arte y mercado, o quizá, mejor, belleza y dinero, nos suscitasen una especie de incompatibilidad de conciencia: la belleza artística estaba asociada al placer visual, un sentimiento desinteresado por antonomasia, no puede ser tasado. Tendemos a enmascarar la circunstancia económica del arte bajo términos tales como gusto, mecenazgo, coleccionismo, preservación de patrimonio, turismo, extensión cultural, identidad o protección a la creación [...] en el mundo contemporáneo (las obras de arte) han estado y están sometidas a intereses económicos como cualquier otro producto de consumo. Es evidente que el arte constituye una mercancía que se compra y se vende. Como a toda mercancía, por lo tanto, la sociedad les concede un valor y la ley de la oferta y la demanda termina por ponerle un precio (Reyero 2009: 1).
}

En el mercado del arte y antigüedades esa dimensión económica se materializa, interviniendo para ello muchos y muy diferentes factores, algunos inherentes a la pieza como son la calidad, la antigüedad, el diseño, el 
ebanista que la realizara, la riqueza de los materiales empleados y, por supuesto, su estado de conservación. Otros, sin embargo, vienen determinados por el propio mercado en función de la demanda: la escasez, la originalidad, incluso el lugar y el momento donde se efectúe la venta pueden terminar por condicionar un precio concreto. Además existen otros factores a tener en cuenta relacionados con los posibles avatares de una determinada pieza, tales como su destino, para quién o para dónde fue concebida, o los propietarios que haya podido tener a lo largo de su historia, que pueden dotarla de un aura especial que en el circuito comercial se traduce en una revalorización económica respecto a otras de similares características. Sirva como ejemplo una mesa escritorio victoriana en madera de caoba y una silla en nogal, muebles ambos del siglo XIX vendidos en pública subasta por un precio final de $548.495 €$, algo a todas luces incomprensible, a no ser por el hecho de que fueron utilizados en su día por Charles Dickens ${ }^{1}$. Más flagrante aún es el caso del asiento más caro del mundo, vendido en 2009 por casi 22 millones de euros, resultando el segundo mueble por el que más se ha pagado en la historia. La butaca, conocida como the Dragon chair, un diseño de la arquitecta y artista irlandesa Eileen Grey (1878-1976), perteneció, y lo tuvo como favorito en vida, al modisto francés Yves Saint Laurent $^{2}$, lo que hizo subir su precio final hasta cotas tan desmedidas.

Por tanto, en el ámbito económico, el mueble, como cualquier otra obra artística, está sujeto a factores socioculturales que hacen que determinadas piezas alcancen precios muy destacados sin tener porqué ser excepcionales desde un punto de vista estético, artístico o histórico. Este punto se pone especialmente de manifiesto por otra circunstancia, la inapelable vinculación existente entre decoración y mobiliario, que somete a esta disciplina, a nivel comercial, a los vaivenes de "lo que dicta la moda". Por ejemplo, en los últimos años se viene constatando un interés general en decoración por el mueble oriental, especialmente chino y tibetano, lo que se ha traducido en una ingente cantidad de piezas salidas a mercado, de una calidad muy desigual y en ocasiones con precios desorbitados. La misma lectura puede hacerse para el mueble de diseño del siglo xx, que se impone en decoración como una de las últimas tendencias, lo que provoca que se paguen simples copias casi como originales, y como, efectivamente, se venden, llegan a inundar el mercado de arte y antigüedades.

En este mismo sentido, pero en otro orden de cosas, los muebles producidos en ámbitos locales con una marcada identidad cultural también al-

\footnotetext{
${ }^{1}$ Christie's Londres, 4 de junio de 2008, con una estimación inicial de 50.000-80.000 Libras.

${ }^{2}$ Christie's Londres, 23 de febrero de 2009, con una estimación inicial de 2.000.0003.000.000 de euros.
} 
canzan precios por encima de mobiliario de similares características y épo$\mathrm{ca}$, producido en otros lugares. Este fenómeno que podríamos denominar como "localismo" suele estar refrendado por una clase empresarial con poder adquisitivo elevado, dispuesta a invertir en piezas vinculadas a su lugar de origen. En España quizá el caso más paradigmático sea el de Galicia, y aunque no son los muebles la prioridad de aquellos compradores, también puede hacerse esta lectura a través de los precios que estos, comparativamente, alcanzan.

\section{AGENTES DE MERCADO}

Las subastas y el comercio del mueble: valoración bistórica. El caso español

Aunque de hecho ya los griegos, y antes los egipcios ptolemaicos, utilizaban este sistema, la antigüedad de las subastas como forma de venta de objetos queda patente en el propio término, cuyo origen (tanto en español como en italiano) deriva de la expresión latina sub hasta venditio - vender bajo el asta - reflejo de la costumbre romana de clavar un asta militar en el lugar donde se realizaba la venta del botín y de los prisioneros de guerra. Asimismo el inglés y alemán toman el vocablo de la voz latina auctio, ascender, en relación al proceso de venta (García Morcillo 2005: 13-15).

Desde el siglo XVI se generaliza en España la almoneda como medio de venta tras el fallecimiento de una persona de determinado rango. Definida por el Diccionario de Autoridades como "la venta de las cosas que públicamente se hace con intervención de la justicia y a voz de pregonero, que publica la cosa que se vende y el precio que dan por ella, para que vayan pujando unos a otros los compradores y se acreciente el precio y el remate". La duración de la almoneda venía determinada por la venta del último objeto, prolongándose a veces durante meses.

Esta forma de liquidación de bienes fue común a toda Europa, sobre todo en las casas regias y nobles "una de las cosas más notables y que más holgaba en la corte eran las almonedas porque en muriendo un señor o una mujer se vende cuanto hay en la casa" son las palabras de Pinherio da Veiga en La Fastiginia, recogidas por Aguiló (1990: 33). Caso paradigmático fue la hoy conocida como "Almoneda del siglo", de la colección de Carlos I de Inglaterra celebrada, tras su ejecución, en 1649, donde Felipe IV adquirió algunas de las más importantes obras que hoy cuelgan en las paredes del Museo del Prado, y a la que la pinacoteca madrileña dedicó una exposición hace algunos años. Esta costumbre llega incluso hasta bien entrado el siglo Xx, y así en 1931 tras la muerte de la Infanta Isabel de Borbón, 
"La Chata", se celebró la almoneda de sus pertenencias. Debió ser uso extendidísimo, anunciándose en prensa y poniendo a la venta objetos de lo más variopinto en cuanto a condición y calidad, justificada por defunciones, traslados, cierres de negocio o incluso matrimonios frustrados ${ }^{3}$. Una viñeta satírica firmada por Juan Pérez Zúñiga aparecida en prensa a finales del siglo XIX se hace eco de este tipo de ventas, con buena dosis de hu$\operatorname{mor}^{4}$ (Fig. 1).

En la actualidad el concepto de subasta se puede definir, de manera general, como una "venta basada en un proceso de licitación en el que el autor de la mejor puja se convierte en el comprador del bien" (Gaspar de Lera 2005: 23). Hoy día éstas además ofrecen, dado su carácter oficial y público, los parámetros que hacen posibles las valoraciones económicas. Es decir, partiendo de los precios estipulados como de salida y, fundamentalmente el del remate obtenido, se realizan las previsiones de valoración económica para piezas similares. Teniendo para ello en cuenta todo tipo de salvedades y factores adicionales, como se ha venido advirtiendo.

Los negocios modernos de subastas aparecen en el siglo XVIII en Londres $^{5}$ donde a partir de 1731, ante la ingente cantidad de copias de arte y antigüedades que invadían el exitoso mercado, comienzan a legislarse. Es entonces cuando nacen las dos grandes casas de subastas conocidas a nivel internacional, Sotheby's, creada en $1744^{6}$, dedicada en un primer tiem-

3 Muy sonada y totalmente excepcional fue en Madrid la exposición y subasta de los bienes de la Casa Ducal de Osuna por ruina del X Duque. Concebida quizá como la primera subasta moderna realizada en España, con la edición de un catálogo en el que además de recogerse las piezas, agrupadas por categorías y su valor valor de tasación, se señalan las normas y codiciones que regirán el proceso de compra, muy similares a los que se utilizan en la actualidad. (Narciso Sentenach. Catálogo de los cuadros, esculturas, grabados y otros objetos artisticos de la antigua Casa Ducal de Osuna, expuestos en el Palacio de la Industria y de las Artes. Segunda edición, corregida y aumentada. Madrid, Est. tip de la Viuda é Hijos de M. Tello, 1896).

${ }^{4}$ A modo de catálogo ilustra algunos de los muebles del supuesto difunto que la viuda pretendería vender bajo el reclamo de “¡Gran Almoneda!”, así un dibujo de una silla cochambrosa en la que no queda un solo muelle en su sitio se presenta con el número uno del catálogo bajo el epígrafe "Preciosísima butaca de palo santo, con mezcla de palo dulce, la construyó un boticario durante la guerra de África para el rey Felipe IV", o una mesa de comedor, igualmente maltrecha, el número diez del catálogo, de la que se acaba por aclarar " (Es mueble en buen uso; aunque me ha manifestado su dueña que necesita patas nuevas en el acto.) Nota. No tiene tablero”. Pérez Zúñiga (1891: 12).

5 Se consideran las casas de subastas más antiguas del mundo a Spink de Londres en funcionamiento desde 1666 y dedicada principalmente a monedas y la Auktionsverk de Estocolmo, fundada en 1674.

${ }^{6}$ Fundada por Samuel Baker a quien se asociaría Georger Leigh, y más adelante su sobrino Jonh Sotheby, familia que abondonó la sociedad en 1861, aunque mantuvo su nombre. 


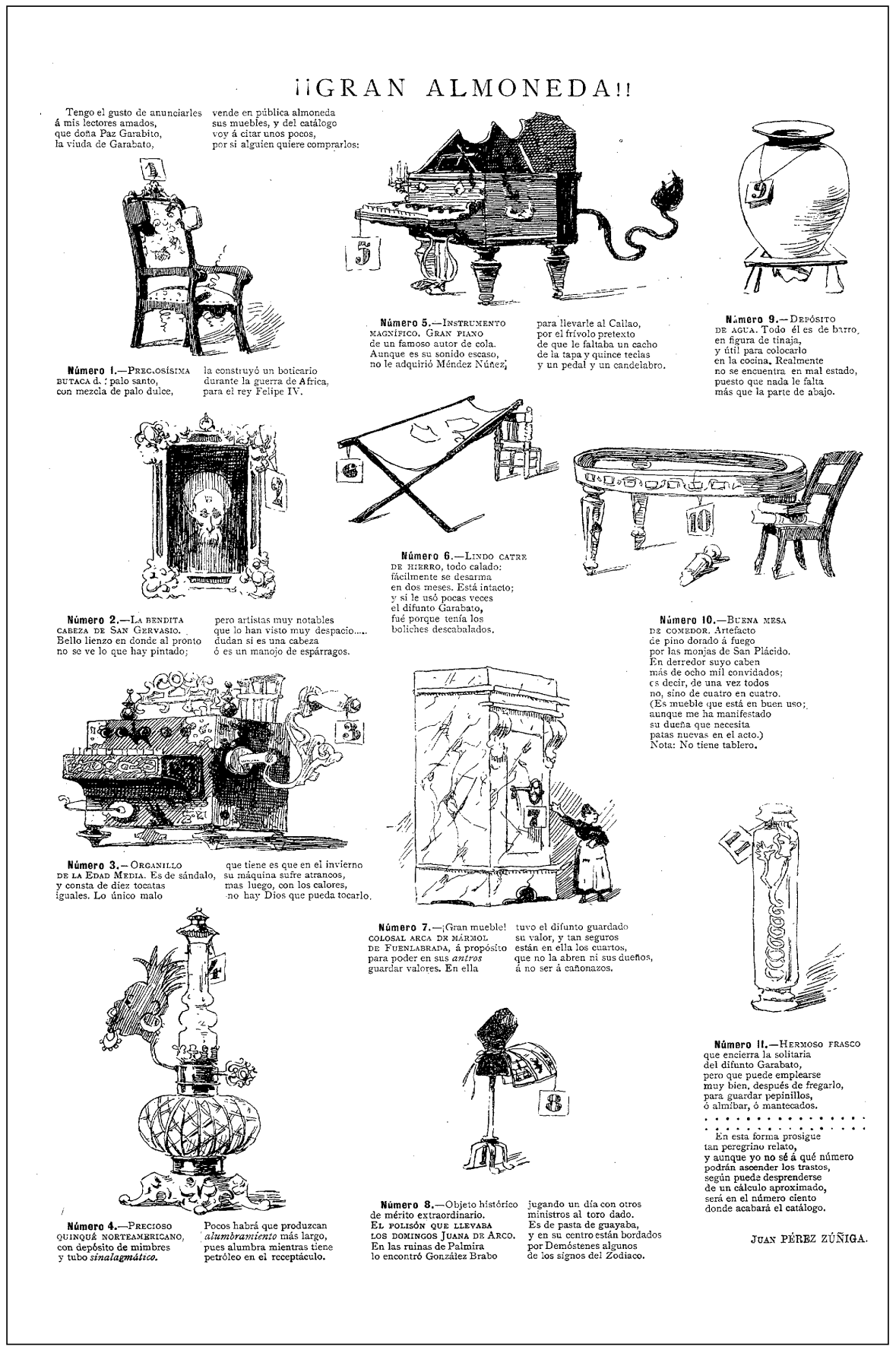

Figura 1. “Gran Almoneda!” Blanco y Negro, 12 de julio de 1891. 


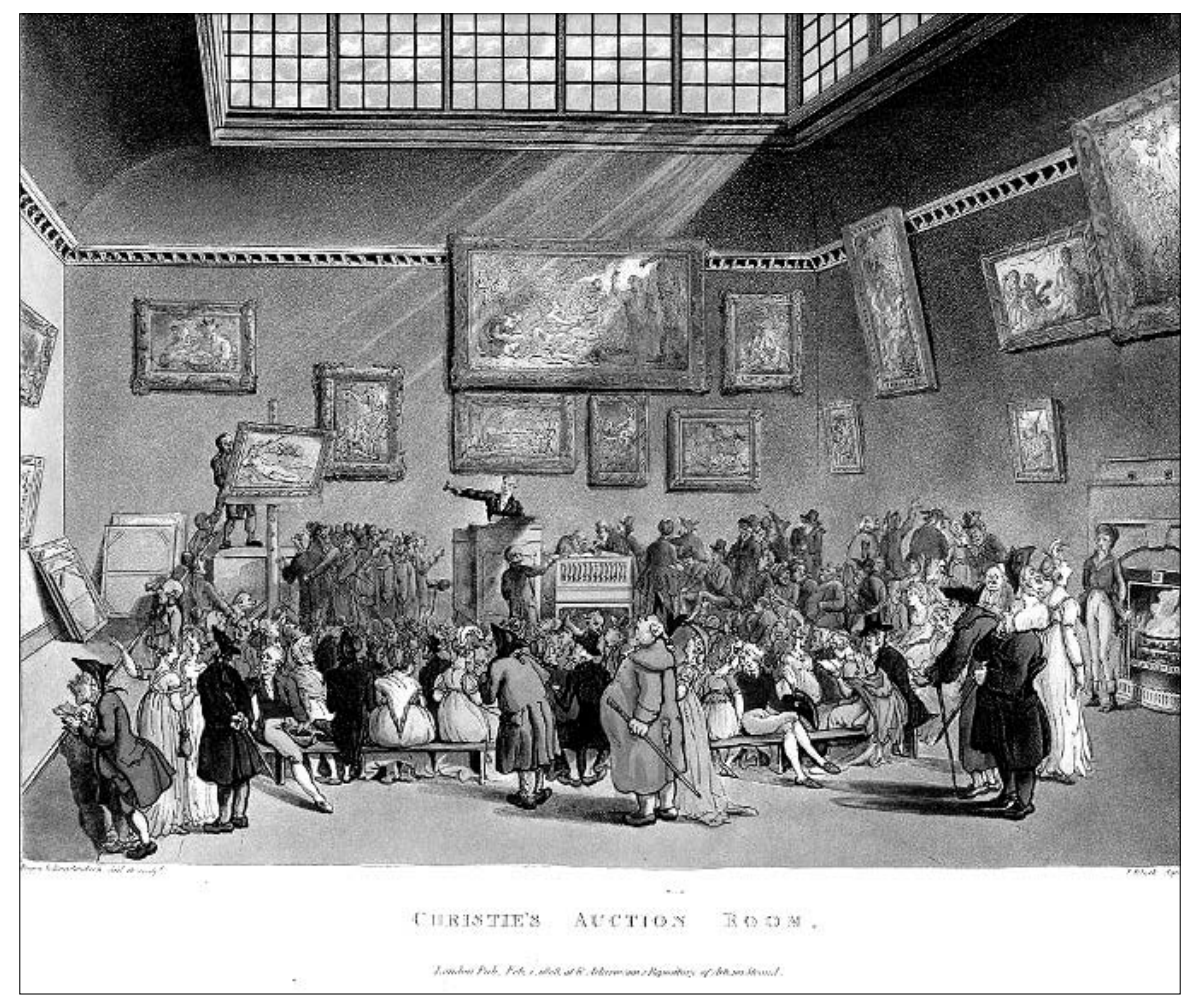

Figura 2. "Sala de subastas de Christie's", dibujo de Thomas Rowlandson y Augustus Pugin para The Microcosm of London. 1808.

po a libros y manuscritos; fue a principios del siglo XIX cuando incorporó lotes de pintura y artes decorativas (Armañanzas 1993: 37) ${ }^{7}$. James Christie fundó poco más de veinte años después, en 1766, la firma que lleva su nombre, dedicada desde su nacimiento a la venta de objetos de arte (Fig. 2).

Con la Revolución Francesa se establece un punto de inflexión para el mercado de arte a nivel internacional, cuando numerosas obras y objetos artísticos pertenecientes a la nobleza salieron del país galo con destino a Londres, siendo entonces la capital inglesa centro de las subastas de arte.

\footnotetext{
${ }^{7}$ Según la autora, Peter Cecil Wilson quien fue presidente de la compañía entre 1958 y 1980 y anteriormente había desempeñado el cargo de director de subastas, dio un giro al poner en venta obras de arte y objetos hasta entonces ajenos a este tipo de ventas. "Sellos, monedas, joyas, vinos, muebles, coches, armas, bastones, instrumentos científicos, alfombras, fotografías, objetos de personajes famosos son ya habituales en las subastas de arte".
} 
Asimismo, diferentes acontecimientos históricos acaecidos durante el siglo XIX en otros países como España, Rusia, Holanda o Prusia obligaron a la aristocracia, hasta entonces la gran poseedora de obras de arte, a desprenderse de sus colecciones que pasaron a engrosar el circuito comercial. Durante el siglo Xx cambian los protagonistas, pues es la burguesía tanto de la vieja Europa como del Nuevo Continente quien va cobrando el protagonismo en la adquisición de obras de arte. Sin embargo se vive un proceso similar ante determinados hechos, de manera especial con el crack de la Bolsa de Nueva York en 1929 y las dos guerras mundiales. Precisamente los casos más conocidos de dispersión de obras de arte se dieron en la Alemania de Hitler a través del saqueo en toda la Europa ocupada de importantes colecciones de adineradas familias de origen judío, muy conocidos son los casos de los Rothschild ${ }^{8}$, Wildenstein, Rosenberg o Kahn.

Las subastas de arte alcanzan mayor peso a nivel internacional tras la II Guerra Mundial. París, por aquel entonces, se presentaba como la primera potencia del mercado, sus salas tuteladas por el Estado facturaron en los años 1951-1952, 3.470 millones de francos, mientras que Sotheby's y Christie's juntas no llegaron a los 2.500. A lo largo de la década de los 60 la capital francesa dejará de ser el centro más importante de subastas de arte, coincidiendo con la apertura de sucursales de las casas inglesas, primero en otros lugares de Europa y posteriormente en Estados Unidos. Concretamente Sotheby's abre sus puertas en Nueva York en 1955, adquiriendo en 1967 Parke-Bernet, la casa de subastas de objetos de arte más grande de América. Christie's sin embargo no desembarcó en suelo americano hasta 1977 (Armañanzas 1993: 35-39, 48).

Durante la década de los 70 es cuando el mercado del arte comienza a cobrar verdadero protagonismo en España. Hecho éste favorecido por una sociedad cambiante con un mayor nivel cultural y una percepción general de mayores posibilidades en cuanto a sus expectativas económicas. Todo ello se ve refrendado por la incipiente creación de la infraestructura necesaria para asentar las bases de lo que conducirá a lo que se ha dado en llamar la socialización de la cultura, con la aparición de nuevos museos, fundaciones, galerías de arte y, también, de casas de subastas. Es en este contexto donde nace la que se consolidará hasta nuestros días como la más importante feria nacional de arte y antigüedades, cuando aparecen los primeros negocios españoles de subastas y cuando las firmas internacionales Sotheby's y Christie's celebran sus primeras licitaciones en nuestro país.

\footnotetext{
${ }^{8} \mathrm{El}$ inventario realizado por los nazis alcanza los 5.000 objetos, y aunque no fue lo habitual la mayoría de ellos fueron restituídos a sus legítimos dueños al término de la guerra.
} 
A este respecto Castedo Moya (1974: 11) recogía en un artículo publicado en la revista Cambio 16 a finales de 1972:

Por las buenas o por las malas este país se civiliza. Primero se acabaron las hambrunas; después pudimos montar en coche, y ahora hasta el arte se puso de moda. Y tan de moda se puso que en el plazo de dos o tres años ha dado lugar a un boyante mercado en el que muchos centenares de millones de pesetas se invierten en bienes tan poco "camp" como óleos, acuarelas o esculturas [...] Las razones de este reciente estallido del mercado son muchas: subida general del nivel de vida, fortalecimiento de un nuevo sector de ejecutivos y profesionales cultos y bien pagados, aparición de muchos potentados enriquecidos en la vorágine de la industrialización [...]. El hecho de que la pintura española, especialmente la del siglo pasado, fuera casi desconocida y estuviera, por tanto, claramente infravalorada, contribuyó sin duda a hacer aún más atractivo el mercado [...] quizá valga más la especulación en un mercado boyante que la vuelta al hermetismo del monipodio o del Rastro.

Las salas de subastas se revelan pues como una novedad que irrumpe con fuerza en el panorama del comercio del arte en España hasta entonces en manos de los anticuarios, lo que supondrá un hito en el sector, ya que por su condición de venta pública —en el más estricto sentido del término- ofrecen, por lo menos en principio, la manera más transparente y rápida de acceder, tanto a las propias piezas, como a las cuantías en que estas han sido adquiridas, a diferencia de las tiendas de anticuario donde los precios son prácticamente inaccesibles 9 .

Un artículo del diario $Y a$ se refería a la nueva modalidad de comercio artístico en los siguientes términos:

[...] Las subastas son por tanto necesarias. Ellas demuestran que esta clase de mercancía no recuerda a ninguna otra. Que el arte se da a quien quiere pagarlo, pero su misterio no pasa de ser de quien quiere, si no de quien puede. [...] da igual comprar con fines de inversión, especulación, jactancia, juego o cariño. Lo interesante es que el arte circule, compita, acceda a ser de uno o de otro, penetre en las casas y quede en estas a la expectativa de ser lanzado nuevamente cuando las circunstancias lo aconsejen. Estoy seguro de que algunos compradores de este tipo no podrán, cuando las circunstancias lo aconsejen, desprenderse de lo que adquirieron como acciones de bolsa o solares para el día de mañana (Faraldo 1971: 34).

El peso específico mayor de las subastas correspondía, entonces y ahora, a la pintura ${ }^{10}$. Las artes decorativas —incluido el mobiliario-, siguen sien-

\footnotetext{
${ }^{9}$ En este sentido se puede afirmar que en la actualidad se está dando un paso más allá, gracias a las nuevas tecnologías, de manera especial con las subastas on line.

${ }^{10}$ En 2006 se realizaron 9.200 subastas, poniendo en circulación 400.000 lotes de los que el 47,6 \% eran pinturas (Tendencias del Mercado, abril 2007: 60).
} 
do tratadas como de segundo orden. En este sentido cabe utilizar el mismo razonamiento que el autor del artículo citado empleaba para referirse a la valoración por aquel entonces de la pintura española del XIX. El desconocimiento y la escasez, hasta el momento, de rigurosos trabajos de investigación sobre mueble contribuyeron a la falta de valoración general, en todos los sentidos. Como se ha comentado al principio, será en estos años cuando se empiece a tratar a las piezas de mobiliario con cierta continuidad en clave científica, lo que equivale a su adecuado conocimiento y por tanto a su consideración.

Así pues, durante los primeros años de la década se produce lo que la prensa y medios especializados de la época denominaron como un auténtico boom de esta nueva forma de compra-venta en el mercado español. En el año 1973 se contabilizaban once casas de subasta en Madrid, dejando al margen aquellas que funcionaban como tales de manera esporádica (Gazeta del Arte 7, 1973: 29) y hacia la mitad de la década llegaron a convivir hasta dieciocho, descendiendo a cinco a finales (G. Maroto 1977: 61). La primera sala española en funcionar de una manera ordenada y regular fue Subastas Durán, que celebró su primera licitación en mayo de 1969. No será hasta la subasta núm. 12, acaecida los días 21 y 22 de octubre del 1970, cuando por primera vez aparezcan muebles entre las piezas de su catálogo. A partir de entonces se irán ofertando de manera intermitente e irregular. No obstante, salieron a la venta algunas piezas interesantes y el mercado a través de su precio de remate se hizo eco de ello. En marzo de 1974 salió a pujas una cama barroca de ébano con aplicaciones de bronce dorado que subió desde las quince mil pesetas iniciales hasta las doscientas cincuenta mil. En el mismo año un arcón español recubierto de cuero del siglo XVII alcanzó un precio de remate de ochocientas mil pesetas, habiendo partido en un inicio de setenta mil. Resulta indicativo que en el artículo de la época del que se han extraído los datos se defina a este tipo de objetos como "lotes aparentemente sencillos y de escaso interés" y se achaque que "puedan alcanzar precios insospechados si se encuentra por medio la honrilla de dos coleccionistas testarudos" (G. Maroto 1977: 62). Es este un factor que ha existido siempre, intrínseco a la esencia de las subastas, pero la aseveración parece excesiva; aparente reflejo de la falta de estima por el mobiliario en el momento, pues era considerado por la generalidad un capricho o una curiosidad más que un objeto artístico poseedor de una dimensión económica que, al igual que la pintura, pudiera ser tratada, en este sentido, como una inversión. Tampoco hay que obviar las estrategias comerciales de cada negocio a la hora de estimar los precios de salida. Así lo recogía una crónica sobre una subasta, de una publicación especializada del momento: 
Y ya que estamos a nivel de caprichos, nada más indicado el comentario de los "varios" de las subastas Durán. Cuando llega el turno de las cerámicas, los marfiles, los iconos, los muebles, etcétera, lo mejor es olvidarse de la palabra "lógica" y asistir estupefacto al espectáculo que se desarrolla cada mes en las sala de Serrano 12. [...] Durán comienza siempre por marcar precios de salida bajísimos a cada lote de "varios". Esto crea un ambiente electrizado en la sala, donde siempre hay alguien que sueña en llevarse uno de esos objetos a su casa en un precio ridículo. El resultado es muy distinto. Lo que normalmente allí se paga supera con creces los cálculos más optimistas. Así pudimos ver como una sillería de caoba, isabelina, del XIX, llegaba a las 210.000 ptas. salía en 35.000. El estado de conservación de las 12 sillas, dos sillones y un canapé no era nada atrayente, pero esto no debió ser obstáculo [...] (Gazeta del Arte 19, 1974: 27 y 28).

En 1973 Christie's celebra en España su primera subasta, los días 13 y 14 de diciembre, en el Hotel Palace de Madrid. Aquella puja se reveló como todo un evento social, así lo recoge unos años después G. Maroto (1977: 61): "El martillo fue manejado por el Archiduque de Austria, doctor Geza Gellet von Habsburg, y estuvieron presentes los más importantes coleccionistas de arte de todo el país". Muy descriptiva del ambiente que allí se vivió resulta la crónica que a ese propósito se publicó en la Gazeta del Arte:

La subasta de Christie's ha constituido un show de repercusión nacional. Las mil y pico plazas del salón Medinaceli ${ }^{11}$, del Hotel Palace de Madrid, estuvieron cubiertas por un público, no solo madrileño, sino de muchísimas provincias. [...] Y de este modo llegaron a la coronación del show, en el cual fotógrafos, periodistas y cámaras de televisión amén del brillante aderezo y empolvado de muchas señoras, dieron al show una lucida apariencia de festejo high society (Gazeta del Arte 13, 1973: 26).

La primera sesión estuvo dedicada a pintura española de los siglos XIX y xx, mientras que la segunda acogió muebles franceses, porcelana europea, tapices y algo de pintura antigua. Se batió entonces el récord de mobiliario, pagándose por una mesa escritorio Luis XV en madera de tulípero la cantidad de dos millones doscientas mil pesetas. En su segunda subasta en Madrid, celebrada en junio de 1974, los muebles tuvieron una buena acogida entre los compradores, destacando un brasero hispano-morisco del siglo XV que se remató en 380.000 ptas. (Gazeta del Arte 24, 1974: 27).

\footnotetext{
${ }^{11}$ Ante la novedad comercial era habitual la masiva afluencia de público como acontecimiento social a las licitaciones, así según recogen las crónicas del momento salas de subastas acogían cientos de espectadores. "La fuerza de seguridad tuvo que cerrar a las once de la noche el acceso a la sala, materialmente repleta de asistentes, que desbordaban pasillos y escaleras. Varios centenares de personas hubieron de esperar en la vía pública la posibilidad de hallar un sitio hasta que, perdida toda esperanza, hubieron de renunciar a su propósito. Otros aficionados siguieron el desarrollo de las ofertas desde el portal y desde la misma calle". ABC Sevilla, 30 de mayo de 1971: 53.
} 
A partir de estas fechas, y probablemente contagiados por los éxitos de Christie's, las piezas de mobiliario van apareciendo con mayor frecuencia en las subastas españolas. Cuando las obras son de interés, los medios de comunicación se hacen eco de ventas y remates, y esto genera que se dediquen espacios a ilustrar al lector sobre el "buen mueble"12.

En 1975 la casa inglesa — siete licitaciones después de su aperturasuspendió las subastas en España - aunque mantuvo una oficina abierta en Madrid, principalmente dedicada a labores de intermediación-, achacándose el cese de las ventas a la falta de rentabilidad, entre otras cosas, por el entonces vigente impuesto del lujo, que gravaba los precios de los artículos con un 24,20\% $\%^{13}$. Casi veinticinco años más tarde, en 1999 celebró de manera extraordinaria una subasta en España que quizá haya sido, en su conjunto, la más importante celebrada hasta la fecha en lo que respecta al mueble español. Se trató de una House Sale donde salieron a la venta todos los enseres: pintura, mobiliario, escultura, textiles y demás objetos, del castillo de Bendinat y Ca'n Puig en Mallorca, alcanzando un valor por el total de los lotes de 1.249.705.000 pesetas, batiendo récords de venta en todos los ámbitos ${ }^{14}$.

En el apartado de mobiliario salieron a pujas trescientos cuatro muebles datados entre los siglos XVII y $\mathrm{xx}$, que obtuvieron una recaudación total de alrededor de cuatrocientos seis millones de pesetas. La cifra más alta la pagó un coleccionista americano por una pareja de armarios vitrina mallorquines en madera tallada, dorada, pintada e incisa (Fig. 3). Superaron el precio máximo nunca pagado por un mueble en España, con un remate de cincuenta millones de pesetas, dejando atrás los treinta y dos millones obtenidos un año antes por un secrétaire francés del siglo XviII vendido en Castellana Subastas en Madrid (Mateos 1999: 29). Entre el mobiliario destacaron de manera contundente otros remates, como los pagados por una pareja de mesas italianas de scagliola adquiridas por un marchante británico en unos treinta millones y una pareja de escritorios napolitanos con escenas en vi-

${ }^{12}$ Así lo hacían los dominicales de los periódicos, y otras publicaciones como La Gazeta del Arte solicitando a los especialistas en la materia su opinión sobre determina-dos tipos. Esta práctica continúa en la actualidad en revistas del sector y también en publicaciones no especializadas como diarios generales o revistas dedicadas a la decoración.

${ }^{13}$ G. Maroto (1977: 64), recoge las palabras que en 1975 ofreció el director de la sala, D. François Curiel, al respecto: "No queremos comprometer nuestro prestigio de subastadores puros, creemos que aquí no se pueden realizar verdaderas subastas. Los altos impuestos nos obligan a comprar pinturas baratas para sacarla nosotros mismos a subasta y no hemos venido aquí a hacer la competencia a los comerciantes".

${ }^{14}$ En lo que respecta a pintura la mayor recaudación la obtuvo un bodegón del maestro de Hartford activo a finales del xvi que se remató en 180 millones de pesetas. 


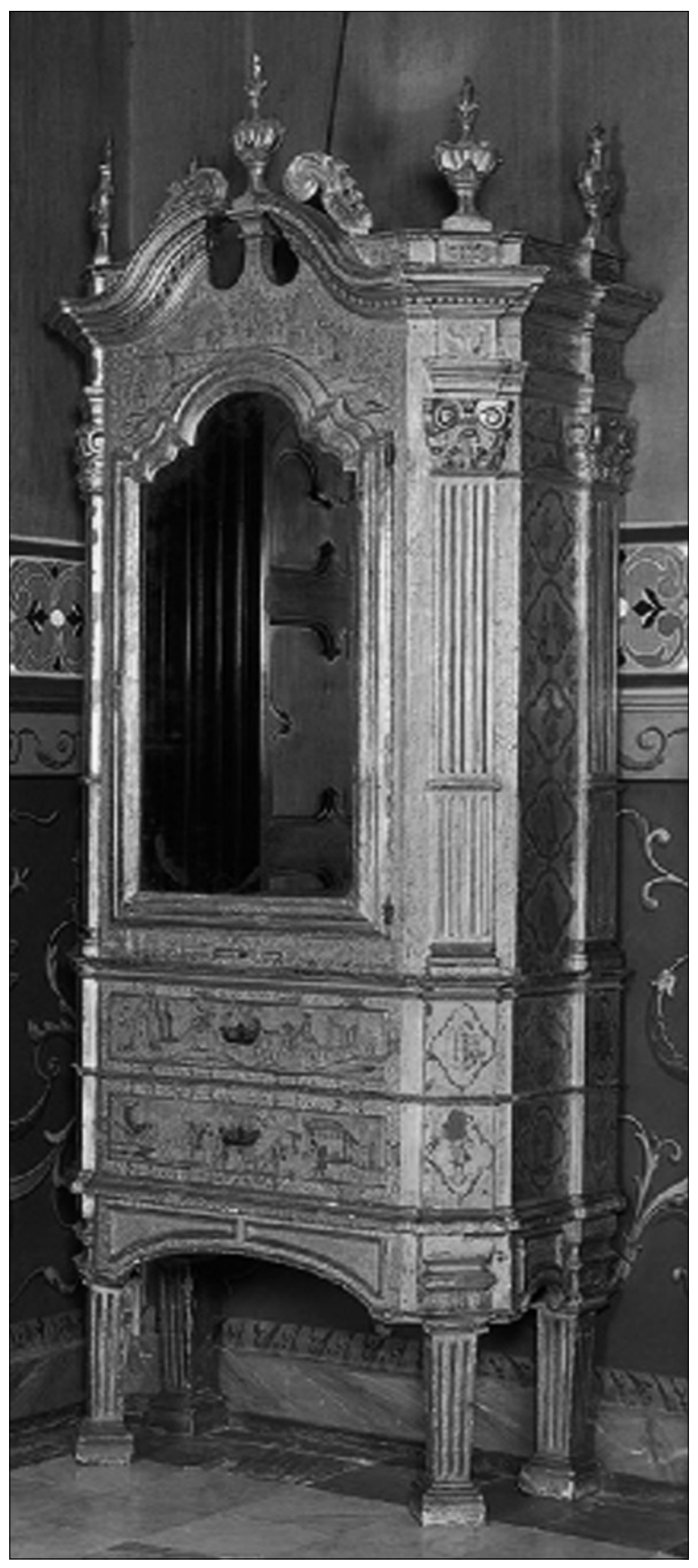

FIGURA 3. Pareja de armarios vitrina mallorquines (uno de dos), siglo XviII. Christie's. Castillo de Bendinat. 1999. 
drio pintado al estilo de Luca Giordano rematados en veintiséis millones de pesetas (Suffield 1999: 44). Resulta esclarecedor el hecho de que, tomando como referencia los diez lotes más caros de mobiliario subastado durante todo el año en España, los ocho primeros fueran piezas vendidas en esta licitación y que, pasada ya más de una década desde su celebración aún se mantengan algunos de los lotes entre los mejor pagados en la historia de las subastas de mueble en nuestro país (Tabla 1). Entre el mobiliario de producción nacional que se vendió, al margen de los ya citados armarios, cabe destacar dos parejas de cómodas. Unas del siglo XVIII, construidas en madera de palo de rosa con tiradores de plata, y fernandinas de comienzos del XIX las otras, atribuidas al taller de Sacanell (siguiendo diseños de su maestro Adrián Ferrá) realizadas en caoba con aplicaciones de bronce. Todas de producción mallorquina, obtuvieron el mismo remate, doce millones de pesetas. Alrededor de los diez millones lograron asimismo otra pareja de muebles, unas consolas españolas del siglo XVIII en madera dorada con tapa de mármol.

\section{TABLA 1}

Muebles españoles mejor pagados en subastas ${ }^{15}$

\begin{tabular}{|c|c|c|c|c|c|}
\hline Fecha & Sala de subastas & Lugar & Objeto & Material/técnica & Remate \\
\hline 2007 & Christie's & Nueva York & $\begin{array}{l}\text { Biombo Antonio } \\
\text { Gaudí (Fig. 5) }\end{array}$ & Roble y cristal esmerilado & $1.385 .000 \$$ \\
\hline 2005 & Sotheby's & Nueva York & $\begin{array}{l}\text { Buró neoclásico. } \\
\text { Gabriel Gómes } 13 \\
\text { de febrero de } 1817\end{array}$ & $\begin{array}{l}\text { Caoba con aplicaciones de } \\
\text { bronce }\end{array}$ & $769.000 \$$ \\
\hline 2007 & Alcalá & Madrid & $\begin{array}{l}\text { Mesa de cartas } \\
\text { náuticas de Juan } \\
\text { Riuvadets }\end{array}$ & $\begin{array}{l}\text { Raíz de Olmo, tuya y maderas } \\
\text { finas }\end{array}$ & $350.000 €$ \\
\hline 2009 & Christie's & Londres & $\begin{array}{l}\text { Pareja de cómodas } \\
\text { Carlos IV, h. } 1800\end{array}$ & $\begin{array}{l}\text { Palisandro, tulípero y marque- } \\
\text { tería }\end{array}$ & $193.250 \stackrel{f}{\&}$ \\
\hline 1999 & Christie's & Mallorca & $\begin{array}{l}\text { Pareja de armarios, } \\
\text { s. XVIII }\end{array}$ & $\begin{array}{l}\text { Madera tallada, pintada, dora- } \\
\text { da e incisa }\end{array}$ & $50.000 .000 \mathrm{pta}$ \\
\hline 2010 & Christie's & Londres & $\begin{array}{l}\text { Biblioteca, Rafael } \\
\text { Contreras e hijo, } \\
\text { Alambra c. } 1890\end{array}$ & $\begin{array}{l}\text { Caoba y tuya, plata galvaniza- } \\
\text { da, hueso y ébano }\end{array}$ & 181.250 \& \\
\hline 2005 & Christie's & Nueva York & Pareja de espejos & Plateado y metal & $192.000 \$$ \\
\hline 2002 & Retiro & Madrid & $\begin{array}{l}\text { Cómoda Carlos IV } \\
\text { con escudo de } \\
\text { Godoy }\end{array}$ & $\begin{array}{l}\text { Palosanto, caoba, nogal y } \\
\text { otras maderas }\end{array}$ & $100.000 €$ \\
\hline
\end{tabular}

${ }^{15}$ Nos ceñimos a los datos y catalogaciones propuestas por cada casa de subastas. 
Coincidió ese mismo año otra significativa subasta para el mueble y el coleccionismo español. La venta tenía como base la colección de Ángel Lucas, uno de los más reputados anticuarios y quizá de los mejores conocedores de mueble español por esas fechas. La subasta fue celebrada el 27 de mayo en Londres por Christie's bajo el epígrafe The Lucas Collection, y aunque se alcanzaron las expectativas depositadas en ella, las mejores obras fueron retenidas por el Estado español, que, debido a su interés, prohibió su salida del país declarándolas inexportables, por lo que no llegaron a ser subastadas. A pesar de todo, algunos de los lotes en licitación rebasaron con creces la estimación dada por los organizadores. La recaudación total ascendió a más de 638.000 libras con 157 lotes vendidos. Dentro de esta subasta y como una de las piezas de mobiliario español más notables se encontraba una mesa extensible de factura aragonesa realizada en madera de nogal y fechada hacia el tercer cuarto del siglo xvI, en muy buen estado de conservación, que partía con una estimación inicial de 12.000-18.000 libras y se remató en 32.200; el mueble en cuestión había sido publicado años antes (Aguiló 1990: 337-338). También significativas por su calidad y su precio de remate fueron una pareja de cómodas mallorquinas de mediados del s. XVIII, que se vendieron en 31.050 libras.

Sotheby's, por su parte, se había unido en 1974 a la casa española Saskia para celebrar subastas en nuestro país, abriendo su propia oficina en Madrid en $1979^{16}$ con motivo de la venta de los enseres del palacio de El Quexigal en Cebreros (Ávila), propiedad por entonces de la familia Hohenlohe, que alcanzó un precio total de venta de 102 millones de pesetas, lo que supuso un récord de recaudación en subastas celebradas en España. Los lotes más numerosos e interesantes correspondían a obra pictórica. En el apartado de mobiliario español las piezas en su gran mayoría pertenecían al siglo XVII, las más caras eran escritorios de tipo mudéjar con una estimación entre 200.000-450.000 pesetas. El Estado español declaró inexportables la mayoría de las obras con lo que, al retirarse los compradores extranjeros, los precios alcanzados no subieron tanto como hubiese cabido esperar.

Excepcionalmente, ambas subastas, El Quexigal y Bendinat, siguieron el modelo de subastas anglosajón, incluyendo la cuidadosa edición de un documentado catálogo en el que se narraba la historia familiar y de la casa

\footnotetext{
${ }^{16}$ En 1985 pasó a funcionar como filial de la casa inglesa bajo el nombre de Sotheby's España S.A. Cuatro años después es adquirida por Edmund Peel, hasta entonces consejero delegado, dando paso a Edmund Peell \& Asociados S.A, con representación exclusiva de Sotheby's en España. En el 1992 Sothebys Holding Inc. volvió a hacerse con el control (Armañanzas 1993: 40-41).
} 
permitiendo conocer las obras en su contexto, algo poco habitual en España, en primer lugar por la propia idiosincrasia de las clases altas españolas, que perciben la venta de las posesiones como algo, en muchas ocasiones, deshonroso. Y en segundo, por pura estrategia comercial de las salas a las que no resulta rentable ediciones tan caras en relación a las piezas que suelen salir a pujas en España.

Un año después, el 2 de febrero de 1980, Sotheby's llevó a cabo otra importante subasta en el hotel Ritz de Madrid, bajo el epígrafe "La decoración en España en los siglos XVIII y XIX", dedicada casi en exclusiva a muebles y objetos. Como pieza más destacada salió a la venta un secrétaire Carlos IV con tapa abatible en caoba y marquetería de limoncillo con herrajes de plata fechado en 1806, rematado por un copete con las armas de la familia Caramany (Fig. 4); pieza muy ligada a las habitaciones de maderas finas de

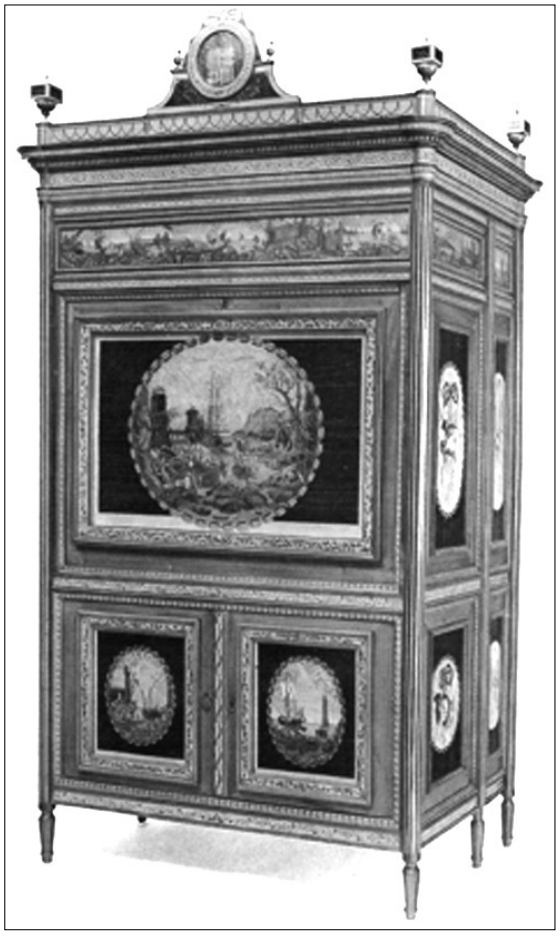

FIgURA 4. Secrétaire Carlos IV con las armas de la familia Caramany. Sotheby's. Madrid, 1980.

El Escorial. En la catalogación se apuntaba la posibilidad de que alguno de sus artífices, Pablo Palencia, Teodoro Oncell o Ángel Maeso, hubiesen intervenido en su ejecución. El mueble se remató en seis millones de pesetas, tras incrementarse el precio de salida en dieciocho pujas, situándose económicamente por encima de otros interesantes lotes, atribuyéndose el mejor resultado de la subasta.

Coincidiendo con el mítico año 1999 Sotheby's dejó de realizar licitaciones en España, manteniendo su oficina en Madrid. Christie's, por su parte, desde octubre de 2004 reanudó su actividad comercial en nuestro país con una única subasta anual, dedicada casi exclusivamente a pintura, esta licitación se ha convertido en punto de referencia para el mercado nacional, tanto por la calidad de las obras, como por los precios que alcanzan.

El panorama actual ofrece una veintena de casas de subastas españolas concentradas en su gran mayoría entre Madrid y Barcelona, casi todas ofertan mobiliario entre las páginas de sus catálogos, pero los grandes co- 
leccionistas y poseedores de piezas prefieren el extranjero para realizar sus ventas donde previsiblemente alcanzarán unas mayores expectativas, así son muchos los ejemplos de interesantes subastas internacionales que se nutren de colecciones españolas.

TABLA 2

Muebles mejor pagados en subastas en España

\begin{tabular}{|c|c|c|c|c|c|}
\hline Fecha & Sala de subastas & Lugar & Objeto & Materialtéénica & Remate \\
\hline 2004 & Alcalá & Madrid & $\begin{array}{l}\text { Arca de bodas de } \\
\text { Juana y Felipe, Flo- } \\
\text { rencia o Milán s. XVI } \\
\text { y XIX }\end{array}$ & Marquetería & $1.000 .000 €$ \\
\hline 2008 & Alcalá & Madrid & $\begin{array}{l}\text { Pareja de espejos } \\
\text { sicilianos s. XVII }\end{array}$ & $\begin{array}{l}\text { Coral, bronce dorado y } \\
\text { esmaltes }\end{array}$ & $650.000 €$ \\
\hline 2007 & Alcalá & Madrid & $\begin{array}{l}\text { Mesa de cartas náu- } \\
\text { ticas de Juan Riuva- } \\
\text { dets }\end{array}$ & $\begin{array}{l}\text { Raíz de Olmo, tuya y maderas } \\
\text { finas }\end{array}$ & $350.000 €$ \\
\hline 1999 & Christie's & Mallorca & $\begin{array}{l}\text { Pareja de armarios, } \\
\text { s. xVIII }\end{array}$ & $\begin{array}{l}\text { Madera tallada, pintada, } \\
\text { dorada e incisa }\end{array}$ & $300.000 €$ \\
\hline 2010 & Fernando Durán & Madrid & Cabinet alemán & Marfil y carey & $250.000 €$ \\
\hline 1998 & Castellana 150 & Madrid & $\begin{array}{l}\text { Secrétaire a abattant. } \\
\text { Francia s. XVIII }\end{array}$ & Roble, nogal y otras & $32.000 .000 \mathrm{pta}$ \\
\hline 2002 & Alcalá & Madrid & Cómoda francesa & & $180.000 €$ \\
\hline 1999 & Christie's & Mallorca & $\begin{array}{l}\text { Pareja de mesas ita- } \\
\text { lianas }\end{array}$ & $\begin{array}{l}\text { Scaggiola, mármol y madera } \\
\text { sobredorada }\end{array}$ & $30.000 .000 \mathrm{pta}$ \\
\hline 2006 & Alcalá & Madrid & $\begin{array}{l}\text { Pareja de espejos } \\
\text { venecianos, h. } 1680\end{array}$ & $\begin{array}{l}\text { Madera tallada, dorada y vidrio } \\
\text { eglomisé }\end{array}$ & $160.000 €$ \\
\hline 1999 & Christie's & Mallorca & $\begin{array}{l}\text { Pareja de bargueños } \\
\text { napolitanos, f. s. XVII }\end{array}$ & $\begin{array}{l}\text { Decorados con cristales pin- } \\
\text { tados }\end{array}$ & $26.000 .000 \mathrm{pta}$ \\
\hline 2003 & Alcalá & Madrid & $\begin{array}{l}\text { Cabinet-secrétaire } \\
\text { Reina Ana }\end{array}$ & Madera lacada & $130.000 €$ \\
\hline 2006 & Alcalá & Madrid & $\begin{array}{l}\text { Biombo escuela me- } \\
\text { jicana } s \text {. xvIII papel } \\
\text { pintado y pan de oro }\end{array}$ & Papel pintado y pan de oro & $130.000 €$ \\
\hline 1999 & Christie's & Mallorca & $\begin{array}{l}\text { Mesa escritorio } \\
\text { Luis XVI }\end{array}$ & $\begin{array}{l}\text { Palma de caoba, bronce } \\
\text { dorado }\end{array}$ & $20.000 .000 \mathrm{pta}$ \\
\hline 2002 & Retiro & Madrid & $\begin{array}{l}\text { Cómoda Carlos IV } \\
\text { con escudo de } \\
\text { Godoy }\end{array}$ & $\begin{array}{l}\text { Palosanto, caoba, nogal y } \\
\text { otras maderas }\end{array}$ & $100.000 €$ \\
\hline
\end{tabular}




\section{Las ferias: reunión de anticuarios}

Las actuales ferias de arte y antigüedades aparecen como resultado de la agrupación periódica de tiendas de anticuarios en un mismo espacio físico buscando, tanto repercusión y estima social, como estimulación de las ventas a través de la apertura de su mercado. Surgidas en parte como respuesta comercial del sector al fenómeno de las subastas, suelen presentarse acompañadas de gran publicidad y las más importantes son tratadas como verdaderos eventos culturales.

A nivel internacional la feria más prestigiosa es la conocida como TEFAF de Maastricht (The European Fine Art Fire). Nació en 1975 bajo el nombre de "Pictura", especializada en pintura antigua y escultura medieval. El éxito de esta feria propició el nacimiento, tres años después, de "Antiqua", rebautizada en 1979 como "Antique Maastrich". Por fin, en 1985 ambas ferias, "Pictura" y "De Antiquairs Internacional" se fusionaron, dando lugar a la actual, que, tras varios cambios de denominación, pasó a conocerse como "TEFAF. Maastrich". Desde la década de los ochenta celebra reconocidas exposiciones en relación con destacados museos. La reputación de esta feria viene avalada por veintitrés comités de investigación integrados por más de ciento cuarenta expertos internacionales que hacen de ella el modelo a seguir principalmente por su rigor en la selección de las obras presentadas. Sólo tres marchantes españoles han sido invitados a participar desde entonces: Luis Elvira, el primer español admitido desde 1992, López de Aragón, desde 1995, y Caylus, desde el año 2001.

En España la feria que cuenta con más prestigio es "Feriarte" inaugurada en 1974 con la participación de setenta y dos anticuarios españoles.

Con las exposiciones y subastas de antigüedades completan el triángulo que encierra el buen momento del mercado artístico en nuestro país. Faltaba acaso que diesen el "gran golpe" manifestativo cara al público. Y lo han dado con Feriarte (Logroño 1974: 93).

La feria volvió a celebrarse en 1976, superando el doble de la cifra de anticuarios que acudieron a la primera cita. Desde entonces se convoca anualmente, en la actualidad bajo el auspicio de la Asociación de Anticuarios de Madrid. Acoge a marchantes de todo el territorio nacional a los que, en los últimos años, se ha sumado un creciente número de expositores internacionales. En la convocatoria de 2006 reunió un total de 208 profesionales, entre los que se incluyen empresas de publicaciones y otros servicios relacionados con el arte y las antigüedades. La feria, que se sitúa entre las cinco más importantes de Europa, ofrece una percepción global del 
mercado español. Sin embargo en los últimos años el número de profesionales de las antigüedades que se dan cita en esta convocatoria ha descendido hasta más de un $30 \%$ en 2009.

Las piezas presentadas en la feria deben ceñirse a ciertos preceptos como que los objetos y muebles posean un mínimo de cien años de antigüedad, salvo aquellas integradas en los estilos Art Decó, Art Nouveau, Eduardino y Alfonsino. La pintura y escultura contemporáneas deben pertenecer a un autor de reconocido prestigio e importancia histórico-artística; por otro lado, la obra en cuestión debe haber sido realizada como mínimo diez años antes de la fecha del certamen en curso. El debido cumplimiento de la normativa, así como la autenticidad de las piezas viene avalada por un Comité Científico, que en los últimos tiempos intenta equilibrar entre sus miembros

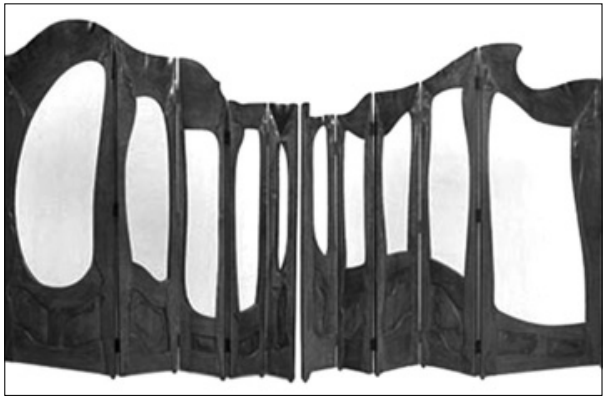

Figura 5. Biombo diseñado por Gaudí en 1901 para la Casa Milá. Christie's Nueva York. 2007. el número de anticuarios con el de especialistas independientes.

En 2006, debido a las dimensiones espaciales alcanzadas por la feria se optó por su sectorización, al estilo de la TEFAF de Maastrich o la Bienal de París. Asimismo se estableció una regulación entre galerías y anticuarios, considerándose las vanguardias históricas y el arte a partir de 1945 como arte contemporáneo; de este modo, el profesional definido como anticuario solo podría tener un máximo

de cinco piezas contemporáneas en su espacio, en tanto que los englobados en el sector de los galeristas podrían exhibir pintura de cualquier época, pero tendrán un limite máximo de cinco antigüedades. Esta medida se conecta con la tendencia actual de compra en la feria, que es la de invertir en pintura de vanguardia española de principios del siglo Xx.

Feriarte se ha convertido en un verdadero acontecimiento cultural en Madrid, y este hecho viene refrendado por el apoyo institucional que recibe. El Museo Nacional de Artes Decorativas apoya la feria con su presencia, ya que cada año se reserva un espacio para la exhibición temática de fondos de sus colecciones. En 2001, coincidiendo con el xxv aniversario de su nacimiento, la muestra estuvo dedicada a las piezas que el museo había adquirido a lo largo de los veinticinco años de vida de la feria, no en vano puede decirse de esta institución que ha sido su comprador más destacado.

El éxito de estas convocatorias ha dado lugar a la proliferación de ferias, algunas con décadas de funcionamiento y otras de más reciente crea- 
ción, no obstante se observa cierta saturación en el mercado, tanto por la cantidad de certámenes convocados como por la proximidad temporal con que se celebran; así, en 2007 el número de ferias dedicadas al arte y antigüedades en el territorio nacional rozó las sesenta convocatorias. Entre las más destacadas en el sector de la antigüedades se sitúan Almoneda y Artemanía en Madrid, Antiquaris de Barcelona, Las Atarazanas en Sevilla, la Feria de Arévalo (Feria de Antigüedades de Castilla y León), Antic Art en Baleares, Anticuarios de Zaragoza, la Bienal de Úbeda, la Feria de antigüedades de Vic, en San Lúcar de Barrameda, en El Puerto de Santa María, en Palencia, Antic Art de Palma de Mallorca, o La Bisbal d'Ampordá, entre otras.

De todo lo expuesto se desprende en que modo el mercado de arte y antigüedades, específicamente con las casas de subastas, y también con las ferias, ha contribuido a la difusión y a la concienciación del patrimonio. Piezas que permanecían ocultas en colecciones, negocios o casas particulares, han visto la luz y han podido ser rescatadas de ese olvido, estudiadas, y las más significativas han ido a completar y enriquecer las colecciones estatales, o lo que es lo mismo nuestro patrimonio. Asimismo piezas importantes localizadas fuera de nuestras fronteras ${ }^{17}$ han podido ser recuperadas. De este modo ferias de arte y antigüedades así como determinadas subastas, que en principio deberían reducirse al ámbito de lo comercial, se han revelado como verdaderos acontecimientos culturales, hecho propiciado principalmente, por la propia naturaleza del objeto de venta.

Tratamiento Del mueble EN EL MERCADO DE ARTE EN la ACTUALIDAD: El CASO DE LAS SUBASTAS.

Entre los años 1987 y $1990^{18}$ las subastas alcanzan el protagonismo del mercado del arte (Armañanzas 1993: 23). Esto se refleja en el mercado de mueble a nivel internacional, que ve subir sus precios en los remates de las subastas, encontrándose ejemplos relativamente frecuentes (en muebles de primerísima línea) que sobrepasan el medio millón de dólares, algunos

${ }^{17}$ El expolio artístico en España tuvo lugar sobre todo antes de la Ley 16/1985, del 25 de junio del Patrimonio Histórico Español. Desarrollada de manera parcial en el Real Decreto 111/986 del 10 de enero, a su vez modificado por el Real Decreto 64/1994 del 21 de enero y el Real Decreto 1680/1991 del 15 de noviembre, las cuales han limitado la salida ilícita de piezas.

${ }^{18} 1990$ se considera el punto álgido del mercado del arte y el coleccionismo en España. En 2006 se dio un incremento de las cotizaciones del 25,4\%, sólo un 5\% por debajo de ese momento. Ese mismo año se produjeron 9.200 subastas poniendo 400.000 lotes a la venta de los cuales el 47,6 \% era obra pictórica. Tendencias del Mercado de Arte, abril 2007.

RDTP, vol. LXVI, n. ${ }^{\circ}$, pp. 197-228, enero-junio 2011, ISSN: 0034-7981, eISSN: 1988-8457, doi: 10.3989/rdtp.2011.08 
con creces, fundamentalmente en mobiliario parísino del siglo xviI de ebanistas reconocidos como Martin Carlin, Jean-Enri Reisener o Roger Lacroix, y Chippendale americano firmado por autores como Thomas Tufft, Thomas Affleck o John Goddard. Precisamente es en 1990, año considerado como el punto álgido del mercado del arte y del coleccionismo, cuando se bate el récord internacional pagado por un mueble en subasta, doce millones y medio de euros alcanzados en Christie's, por el conocido como Badminton Cabinet, último gran trabajo comisionado por los Médicis en Florencia. Esta cota se mantuvo vigente hasta el año 2004, otro momento cumbre en el mundo de las subastas, cuando este mismo mueble salió de nuevo a pujas y batió su propio récord, alcanzando los veintiocho millones de euros ${ }^{19}$.

Sotheby's y Christie's son las

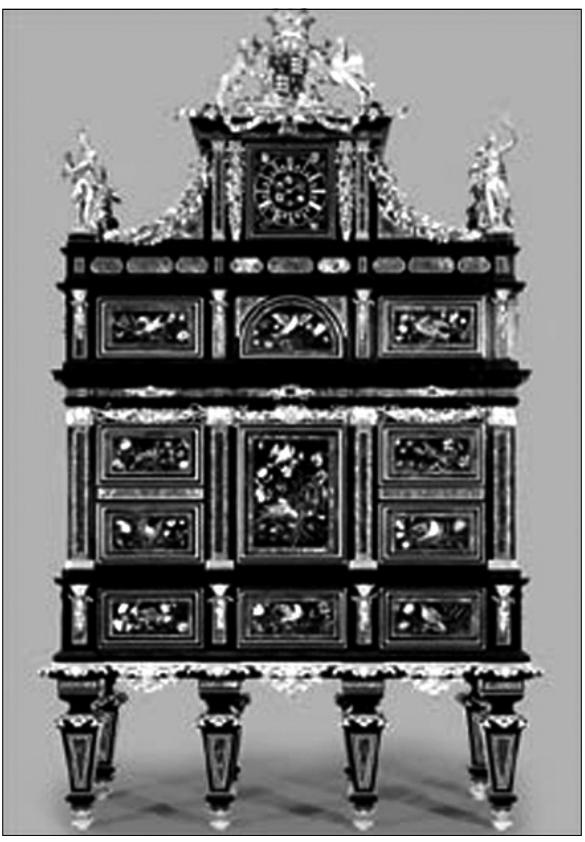

FiguRA 6. The Badminton Cabinet. Christie's, Londres 2004. entidades con un mayor volumen de negocio a nivel mundial (la primera cotiza en el mercado de valores) tienen salas y oficinas por todo el mundo y celebran sus subastas en cuatro continentes. Nueva York y Londres se presentan como los epicentros del mercado internacional de subastas de arte. En lo que concierne a mobiliario y artes decorativas también en París y Milán se celebran algunas de las más destacadas licitaciones (Tabla 3).

En general, el tratamiento que se otorga a los muebles como objetos artísticos en las casas de subasta internacionales dista mucho del que reciben a nivel nacional. Tomando como ejemplo la casa Sotheby's, se observa una estructura interna que engloba quince grandes especialidades que a su vez contienen departamentos más pequeños. En la materia que nos ocupa, dentro de la sección denominada Furniture and Decorative Arts, se incorporan los siguientes departamentos relacionados con mobiliario: 19th century Furniture, sculpture and Decorative

${ }^{19}$ Subastado en Christie's el 11 de diciembre de 2004 es la obra no pictórica más cara vendida en subastas. Adquirida para el Liechtenstein Museum de Viena. 
TABLA 3

Muebles mejor pagados en subastas internacionales

\begin{tabular}{|c|c|c|c|c|c|}
\hline Fecha & Sala de subastas & Lugar & Objeto & Material/técnica & Remate \\
\hline 2004 & Christie's & Londres & $\begin{array}{l}\text { The Badminton Ca- } \\
\text { binet, s. XVIII }\end{array}$ & Piedras duras, bronces, ébano & $28.000 .000 €$ \\
\hline 2009 & Christie's & París & $\begin{array}{l}\text { Drangon Chair, } \\
\text { Eileen Gray, c.1917 }\end{array}$ & Madera lacada & $21.900 .000 €$ \\
\hline 1999 & Christie's & Londres & $\begin{array}{l}\text { Cómoda Luis XVI, } \\
\text { Jean Henri Riesener }\end{array}$ & $\begin{array}{l}\text { Marquetería de maderas finas, } \\
\text { aplicaciones de bronce dorado }\end{array}$ & $7.041 .500 £$ \\
\hline 1989 & Christie's & Nueva York & $\begin{array}{l}\text { Escritorio librería, } \\
\text { Atrib. John Goddard }\end{array}$ & Caoba & $12.100 .000 \$$ \\
\hline 2009 & Sotheby's & Hong Kong & $\begin{array}{l}\text { Trono imperial Di- } \\
\text { nastía Qing, perío- } \\
\text { do Qianlong }\end{array}$ & Madera de zitan & $85.700 .000 \mathrm{HK} \$$ \\
\hline 2005 & Sotheby's & Nueva York & $\begin{array}{l}\text { Mesa de té, Atrib. } \\
\text { John Goddard, c. } 1760\end{array}$ & Caoba & $8.416 .000 \$$ \\
\hline 1999 & Sotheby's & Nueva York & $\begin{array}{l}\text { Mesa-librería Atrib. } \\
\text { Job Townsed y Sa- } \\
\text { muel Casey }\end{array}$ & Caoba y monturas en plata & $8.252 .500 \$$ \\
\hline 2007 & Sotheby's & Nueva York & $\begin{array}{l}\text { Gueridon Table des } \\
\text { Palais Royaux } 1816\end{array}$ & Bronce dorado y porcelana & $6.201 .000 \$$ \\
\hline 2009 & Christie's & Londres & $\begin{array}{l}\text { The March Cucci } \\
\text { cabinet }\end{array}$ & $\begin{array}{l}\text { Madera ebonizada, piedras } \\
\text { duras, carey y bronce }\end{array}$ & 4.521 .250 \& \\
\hline 2010 & Sotheby's & Londres & $\begin{array}{l}\text { Harrintong Commode } \\
\text { c. } 1770\end{array}$ & $\begin{array}{l}\text { Palo de rosa, tulípero y mar- } \\
\text { quetería }\end{array}$ & $3.793 .250 £$ \\
\hline 1998 & Christie's & Nueva York & Cómoda Luis XIV & $\begin{array}{l}\text { Marquetería, metales y montu- } \\
\text { ras de bronce }\end{array}$ & $5.726 .000 \$$ \\
\hline 2011 & Christie's & Nueva York & $\begin{array}{l}\text { Escritorio, Atrib. John } \\
\text { Goddard, c. } 1765\end{array}$ & Caoba & $5.682 .500 \$$ \\
\hline 2000 & Christie's & Nueva York & Newport Chest & & $4.700 .000 \$$ \\
\hline 1990 & Christie's & Nueva York & $\begin{array}{l}\text { Mesa Chippendale, } \\
\text { Thommas Tufft, } \\
\text { c. } 1765-66\end{array}$ & Caoba & $4.620 .000 \$$ \\
\hline
\end{tabular}


Works of Art; 20th Century Decorative Arts \& Design; American Furniture, Decorative Works of Arts \& Folk Art; Arcade: Furniture, Decorative Works of Art \& Carpets; Decorative Arts \& Jewellery; English Furniture \& Decorations; European Furniture; French $\&$ Continental Furniture, Decorations \& Tapestries; General Furniture \& Decorations; Houses Sales.

Cuentan, además, con la colaboración sistemática de los más reputados especialistas académicos en las distintas materias, quienes en muchos casos, son los encargados de elaborar las pertinentes catalogaciones. Poseen publicaciones propias en las que ofrecen amplia información sobre sus subastas a nivel mundial y sobre piezas en concreto, además de los catálogos de ventas en los que se cuidan en extremo la edición, las imágenes y los textos. En todo ello no se debe perder de vista la evidente campaña de marketing que existe; al fin y al cabo el objetivo final es la venta del bien.

En España, por las peculiaridades del propio mercado las casas de subastas actúan habitualmente como generalistas. Un departamento con el nombre genérico de "muebles y objetos" o "muebles y artes decorativas" da cabida a las piezas más variopintas, resultando un panorama bastante irregular, donde se entremezclan muebles de las más diversas épocas, calidades, procedencias y precios. Como consecuencia, y de manera general, las catalogaciones suelen ser poco precisas, dejando a un lado por no ser objeto de este trabajo el espinoso tema de las copias y las falsificaciones que, inevitablemente, circulan por el mercado.

Hasta hace relativamente pocos años las piezas de mobiliario español aparecían frecuentemente mal catalogadas y bajo atribuciones incorrectas, debido a un conocimiento comparativamente inferior en el campo del mueble. Este debería ser hoy un hecho subsanado, pues, en general, existe información suficiente para aportar, cuanto menos, una correcta catalogación del mobiliario. En este sentido se ha de puntualizar que en el mercado internacional, y con un afán presumiblemente comercial, no es extraño que aparezcan piezas de mobiliario español de calidad atribuyendo, no obstante, su origen a otros países (Castellanos 2006: 90). Este hecho tiene su explicación en que, para el comercio internacional, el mueble español ha sido considerado tradicionalmente como un segmento menor, en parte porque son relativamente escasas las piezas de primera calidad en circulación.

La supremacía natural de la pintura sobre cualquier otra disciplina artística, tanto en España como en el extranjero, es una realidad inapelable. Esto se refleja, tanto en la cantidad de piezas que salen a la venta — casi las tres cuartas partes, son lotes de pintura y obra gráfica- como en los precios de remate que alcanzan. La razón hay que buscarla en diversos factores; por un lado es el campo que ofrece un mayor espectro especulativo, lo que atrae a un número elevado de coleccionistas. Por otro lado es el más abun- 
dante y manejable, a la hora de ser transportado y posteriormente ubicado; además de la garantía que para el comprador ofrece la pieza firmada, cosa que de manera general ocurre con las obras pictóricas y no así con el mobiliario, al menos en lo que al caso español se refiere.

No obstante en las últimas tres décadas el mercado de arte y antigüedades ha experimentado una creciente demanda de objetos que se circunscriben dentro del ámbito de las llamadas artes decorativas, convirtiéndose éstas en piezas de coleccionismo e inversión ${ }^{20}$ como alternativa a la pintura.

En concreto, el mercado español de artes decorativas ha ido creciendo en casi todas las áreas. En esto influye, al margen de coyunturas económicas y otros factores circunstanciales, el mayor conocimiento sobre la materia que se ha experimentado en los últimos años. Aunque comparativamente escasas, las mejores piezas españolas pueden competir a nivel internacional en términos de calidad con las de otros países. Sin embargo la escasez de obras así como la falta de tradición de coleccionismo hacen del mercado español un sector irregular y bastante limitado.

Pese a que en líneas generales la venta de mobiliario español dentro del panorama comercial no pasa por su mejor momento, entre las piezas más valoradas económicamente se encuentra el mueble cortesano del siglo XVIII y muy principios del XIX; teniendo en cuenta el perfil del comprador, quizá se deba también a sus dimensiones y a un carácter funcional —alejado de los muebles de aparato de centurias anteriores-, más fácil de acomodar en las viviendas contemporáneas. En este sentido, los tipos de muebles más cotizados, de manera general, son las cómodas, butacas y mesas, ya sean de estilo barroco o neoclásico; todo este mobiliario se caracteriza por una clara influencia europea, francesa e italiana.

En el circuito español el mueble francés de calidad se impone al inglés en lo que a precios se refiere. Sin embargo, ante piezas de calidad similar son las españolas de época de Carlos III y Carlos IV las más cotizadas. Especial interés suscita el mueble de marquetería de este periodo que alcanza los precios más altos, aunque siguen siendo muy inferiores a los que se obtienen en el extranjero. De manera general la "Alta época", los buenos muebles del xviII y el mobiliario de diseño del xx y Art Decó, son las piezas más cotizadas. Mención aparte merece el mueble colonial — de los virreinatos americanos o de las Indias Orientales- muy similar en tipologías a lo español pero realizado con distintos y exóticos materiales que si goza del reconocimiento internacional.

\footnotetext{
${ }^{20}$ Los inicios de la consideración del arte como una inversión económica se establecen en el S. XIX de manera prudente entre algunos marchantes de cuadros. Fue realmente a partir de la década de los setenta cuando se trataron las obras como productos financieros susceptibles de otorgar altas plusvalías. Ver Armañanzas (1993: 102).
} 
A pesar de la falta de tradición en estos negocios y de la modestia del mercado nacional según un informe emitido por la empresa francesa Artprice, en el que se realiza un balance a nivel mundial del mercado de arte - basado en las salas de las subastas-, España ocupa la octava posición en volumen de negocio con un $0.8 \%{ }^{21}$. Según un Informe del Banco de España en 2005 el 18\% de los hogares españoles había invertido en "obras de arte, joyas y diversas antigüedades", convirtiéndose el arte en la tercera opción inversora, tras la inmobiliaria y los productos financieros (GarcíaOsuna 2006: s/n). El arte frente a la inestabilidad del resto de los mercados se muestra como un valor inalterable, lo que en situaciones de crisis provoca que gran parte del capital vea en él una inversión segura.

Aún así el mercado nacional de arte y antigüedades está muy alejado de los grandes centros internacionales encabezados por Nueva York y Londres, tanto en la magnitud de las piezas ofertadas, y en consecuencia de los precios que alcanzan, como en el número de las mismas. Difícilmente se podrían realizar en España, de manera regular, subastas con muebles como únicos protagonistas circunscritos a una época o a un estilo concreto, práctica regular a nivel internacional.

TABLA 4

Adquisiciones del Estado de mobiliario 1999-200722

\begin{tabular}{|c|c|c|c|c|c|}
\hline Año & Objeto & Clasificación & Modo de Adquisición & Precio de adquisición & Destino \\
\hline 1999 & $\begin{array}{l}\text { Atril caoba, hierro } \\
\text { y bronce dorado }\end{array}$ & Graupner 1770 & Derecho de tanteo & $4.640 .000 \mathrm{pta}$ & MNAD \\
\hline 1999 & Tocador & $\begin{array}{l}\text { Mallorca, época } \\
\text { Carlos IV }\end{array}$ & & & MNAD \\
\hline 1999 & Arca ensayalada & Finales s. XV & Oferta de venta & $15.000 .000 \mathrm{pta}$ & \\
\hline 1999 & $\begin{array}{l}\text { Arqueta relicario } \\
\text { Papa Sixto V }\end{array}$ & Finales s. XVI-p. XVII & Oferta de venta & $152.191 .293 \mathrm{pta}$ & MNAD \\
\hline 1999 & Escritorio & $2^{2} \operatorname{mitad} s$. XVII & Oferta de venta & $29.000 .000 \mathrm{pta}$ & \\
\hline 1999 & $\begin{array}{l}\text { Pareja de banque- } \\
\text { tas neoclásicas }\end{array}$ & $1790-1800$ & $\begin{array}{l}\text { Oferta de venta irre- } \\
\text { tas neoclásicas }\end{array}$ & $6.932 .000 \mathrm{pta}$ & \\
\hline
\end{tabular}

${ }^{21}$ Estados Unidos casi $45 \%$, Gran Bretaña 26,9 \% Francia 6,4 \% China 4,9 \% Alemania 2,9 \% Italia 2,8 \% Suecia y Holanda 1,1\% en Antiquaria n.o 260: 3

${ }^{22}$ Datos extraídos de "Adquisiciones de Bienes Culturales". Subdirección General de Protección del Patrimonio Histórico”, Madrid, 1999, 2000, 2001, 2002, 2003, 20042005, 2006 y 2007. 


\begin{tabular}{|c|c|c|c|c|c|}
\hline Año & Objeto & Clasificación & Modo de Adquisición & Precio de adquisición & Destino \\
\hline 1999 & Sillón de aparato & Carlos IV, c. 1800 & $\begin{array}{l}\text { Oferta de venta } \\
\text { irrevocable }\end{array}$ & $3.500 .000 \mathrm{pta}$ & \\
\hline 2000 & $\begin{array}{l}\text { Biblioteca arqui- } \\
\text { tectónica }\end{array}$ & $\begin{array}{l}\text { s. XIX. Planchas de } \\
\text { marquetería }\end{array}$ & Derecho de tanteo & $19.000 .000 \mathrm{pta}$ & MNAD \\
\hline 2000 & $\begin{array}{l}10 \text { dibujos de } \\
\text { proyectos de } \\
\text { muebles y elemen- } \\
\text { tos decorativos }\end{array}$ & $\begin{array}{l}\text { Françesc Vidal } \\
(1880-1900)\end{array}$ & Derecho de tanteo & $154.128 \mathrm{pta}$ & MNAD \\
\hline 2000 & $\begin{array}{l}\text { Dos burós } \\
\text { Jorge III }\end{array}$ & Giles Gredey s. XvIII & $\begin{array}{l}\text { Oferta de venta irre- } \\
\text { vocable }\end{array}$ & $11.856 .000 \mathrm{pta}$ & MNAD \\
\hline 2000 & Caja Boulle & $\begin{array}{l}\text { s. XIX. Oro, lapis- } \\
\text { lázuli, marfil y plata. }\end{array}$ & $\begin{array}{l}\text { Oferta de venta irre- } \\
\text { vocable }\end{array}$ & $6.800 .000 \mathrm{pta}$ & MNAD \\
\hline 2000 & $\begin{array}{l}\text { Arquilla sículo- } \\
\text { normanda }\end{array}$ & $\begin{array}{l}\text { s. XII marfil pintado } \\
\text { y cobre dorado }\end{array}$ & $\begin{array}{l}\text { Oferta de venta irre- } \\
\text { vocable }\end{array}$ & $15.000 .000 \mathrm{pta}$ & MNAD \\
\hline 2001 & Escritorio aragonés & $\begin{array}{l}\text { Mediados s. XVI. } \\
\text { Nogal, hueso y boj. } \\
\text { Técnica del pinyonet } \\
\end{array}$ & Derecho de tanteo & $29.987,50 €$ & MNAD \\
\hline 2001 & Armario-oratorio & $\begin{array}{l}\text { España, 1719. Madera } \\
\text { policromada }\end{array}$ & $\begin{array}{l}\text { Oferta de venta irre- } \\
\text { vocable }\end{array}$ & $54.091,09 €$ & MNAD \\
\hline 2001 & Mesa tocador & Francia, $1760-1780$ & $\begin{array}{l}\text { Oferta de venta irre- } \\
\text { vocable }\end{array}$ & $54.091,09 €$ & MNAD \\
\hline 2002 & Mesa & $\begin{array}{l}\text { Alvar Aalto. Firmada } \\
\text { y fechada } \\
\text { "Finna Ltd. 1935" }\end{array}$ & Derecho de tanteo & $1.408,80 €$ & MNAD \\
\hline 2002 & $\begin{array}{l}\text { Cabinet on stand } \\
\text { con escudo de } \\
\text { armas de Felipe V }\end{array}$ & $\begin{array}{l}\text { Atribuido a Henry } \\
\text { Van Soest, Amberes } \\
\text { c. } 1700\end{array}$ & $\begin{array}{l}\text { Subastas en el extran- } \\
\text { jero }^{23}\end{array}$ & $1.247 .466,00 €$ & MNAD \\
\hline 2003 & Escritorio & $\begin{array}{l}\text { Méjico? h. 1700. Fir- } \\
\text { mado "Bartolomé } \\
\text { Sousa me fecit" }\end{array}$ & Derecho de tanteo & $61.177,47 €$ & MAM \\
\hline 2003 & Cofre nambam & $\begin{array}{l}\text { Momoyama. Laca, } \\
\text { madreperla y latón }\end{array}$ & Derecho de tanteo & $11.740,00 €$ & MNAD \\
\hline 2003 & $\begin{array}{l}\text { Cabinet secrétaire } \\
\text { Reina Ana }\end{array}$ & Inglaterra $1710-1720$ & Derecho de tanteo & $152.620,00 €$ & MNAD \\
\hline 2003 & Espejo & Madrid c. 1755 & Derecho de tanteo & $12.679,00 €$ & MNAD \\
\hline 2003 & Consola & Madrid c. 1755 & Derecho de tanteo & $10.566,00 €$ & MNAD \\
\hline 2003 & Cornucopia & España, c. $1760-1770$ & Derecho de tanteo & $17.613,00 €$ & MNAD \\
\hline
\end{tabular}

${ }^{23}$ Vendido en Sotheby's, Londres el 30 de octubre de 2002, lote 75. 


\begin{tabular}{|c|c|c|c|c|c|}
\hline Año & Objeto & Clasificación & Modo de Adquisición & Precio de adquisición & Destino \\
\hline 2004 & Consola & Madrid c. 1750 & Derecho de tanteo & $6.466,90 €$ & \\
\hline 2004 & Cama barroca & Tercer cuarto s. XVII & $\begin{array}{l}\text { Subasta en el ex- } \\
\text { tranjero }\end{array}$ & $80.600,00 €$ & \\
\hline 2004 & Arca ensayalada & finales $s . \mathrm{XV}$ & Oferta de venta & $55.000,00 €$ & \\
\hline 2004 & Sillón & $\begin{array}{l}\text { Francia, último } \\
\text { cuarto s. xvIII }\end{array}$ & Oferta de venta & $3.000,00 €$ & \\
\hline 2005 & Consola Carlos III & Segunda mitad s. XVIII & Derecho de tanteo & $23.600,00 €$ & MCM \\
\hline 2005 & Cuna & Mongolia, s. XIX & Derecho de tanteo & $118,56 €$ & MNA \\
\hline 2005 & $\begin{array}{l}\text { Sillón de despacho } \\
\text { Carlos IV }\end{array}$ & Caoba, pino, vidrio & $\begin{array}{l}\text { Oferta de venta } \\
\text { eglomisé y bronce } \\
\text { dorado }\end{array}$ & $21.000,00 €$ & MNAD \\
\hline 2005 & Escritorio Carlos IV & $\begin{array}{l}\text { Caoba, palo de rosa, } \\
\text { raíz y latón }\end{array}$ & Oferta de venta & $150.000,00 €$ & MNAD \\
\hline 2005 & Mesa fernandina & s. XVIII. XIX Caoba & Oferta de venta & $2.630,00 €$ & MNAD \\
\hline 2005 & Arqueta Limoges & Francia, p. s .XII & Oferta de venta & $106.650,00 €$ & MNAD \\
\hline 2005 & Arcón Momoyama & Laca y nácar & Oferta de venta & $35.550,00 €$ & MNAD \\
\hline 2005 & $\begin{array}{c}\text { Panel marquetería } \\
\text { de Gaspar Homar }\end{array}$ & $\begin{array}{l}\text { Madera de tuya } \\
\text { y otras }\end{array}$ & $\begin{array}{l}\text { Oferta de venta irre- } \\
\text { vocable }\end{array}$ & $3.261,00 €$ & MNAD \\
\hline 2005 & $\begin{array}{l}\text { Tablero mesa } \\
\text { de piedras duras }\end{array}$ & Roma, c. $1565-1590$ & $\begin{array}{l}\text { Subasta en el ex- } \\
\text { tranjero }\end{array}$ & $750.291,26 €$ & MNAD \\
\hline 2006 & $\begin{array}{l}\text { Sillón episcolar } \\
\text { o capitular }\end{array}$ & $\begin{array}{l}\text { Virreinato del Perú } \\
\text { h. } 1770-1780\end{array}$ & Oferta de venta & $1.304,00 €$ & MNA \\
\hline 2006 & Cama & China, h. 1900 & Derecho de tanteo & $106.650,00 €$ & MNAD \\
\hline 2006 & $\begin{array}{l}\text { Asiento de cere- } \\
\text { monia }\end{array}$ & Costa de marfil s. XVIII & Derecho de tanteo & $2.371,00 €$ & MNAD \\
\hline 2006 & Carrito para niño & China & Derecho de tanteo & $331,96 €$ & MNA \\
\hline 2006 & Estantería & Tafialet, Marruecos & Derecho de tanteo & $355,68 €$ & MNA \\
\hline 2006 & Sofá fernandino & España $1815-1833$ & Oferta de venta & $30.000,00 €$ & MNAD \\
\hline 2006 & Pareja de sillas Sole & España, h. 1850 & Oferta de venta & $7.500,00 €$ & MNAD \\
\hline 2006 & Mesa scagliola & $\begin{array}{l}\text { Nápoles o Sicilia, } \\
\text { tercer cuarto siglo XVII }\end{array}$ & Oferta de venta & $30.000,00 €$ & MNAD \\
\hline 2006 & Cinco espejos & España, mediados XVIII & $\begin{array}{l}\text { Oferta de venta irre- } \\
\text { vocable }\end{array}$ & $35.550,00 €$ & MNAD \\
\hline 2006 & Caja carey & Finales XVII & Oferta de venta & $60.000,00 €$ & MNAD \\
\hline 2006 & Pareja de espejos & España, mediados XVIII & $\begin{array}{l}\text { Oferta de venta irre- } \\
\text { vocable }\end{array}$ & $100.000,00 €$ & MNAD \\
\hline
\end{tabular}




\begin{tabular}{|l|l|l|l|c|c|}
\hline Año & \multicolumn{1}{|c|}{ Objeto } & \multicolumn{1}{|c|}{ Clasificación } & Modo de Adquisición & Precio de adquisición & Destino \\
\hline 2006 & Pareja de espejos & España siglo XVIII & $\begin{array}{l}\text { Oferta de venta irre- } \\
\text { vocable }\end{array}$ & MNAD \\
\hline 2007 & Cofre & Colombia, s. XVIII & Oferta de venta & $25.000,00 €$ & MAM \\
\hline 2007 & Consola & España, 1763-1768 & Oferta de venta & $60.000,00 €$ & MNAD \\
\hline 2007 & Escritorio & taller barcelonés, s.XVI & Oferta de venta & $130.000,00 €$ & MNAD \\
\hline 2007 & Arqueta & España, p. XVI & Oferta de venta & $100.000,00 €$ & MNAD \\
\hline 2007 & Sillería & $\begin{array}{l}\text { París, Francia h. } 1710 \\
\text { Oferta de venta irre- } \\
\text { vocable }\end{array}$ & $266.000,00 €$ & MNAD \\
\hline 2007 & Tocador de dama & $\begin{array}{l}\text { Jennigs \& Bettidge, } \\
\text { Birmingham, tercer } \\
\text { cuarto s. XIX }\end{array}$ & Derecho de tanteo & $8.214,00 €$ & MR \\
\hline
\end{tabular}

COLECCIONISMO DE MOBILIARIO EN ESPAÑA: EL COMPRADOR CIRCUNSTANCIAL, ANTICUARIOS Y MARCHANTES, EL ESTADO

Son muchos los factores que pueden llevar a un individuo a adquirir un objeto artístico, ya sea comprar por el mero placer de poseer y disfrutar la pieza; por alcanzar cierto prestigio social que el objeto artístico puede proporcionar; o simplemente hacerlo como una inversión. En España la figura del coleccionista (base del mercado artístico) de mobiliario, es prácticamente inexistente, ni siquiera son muchas las grandes casas en las que se hayan conservado colecciones importantes por acumulación de muebles ${ }^{24}$, sobre todo en comparación con otros países como Reino Unido. Una de las razones fue en gran medida al carácter inestable que tuvo la corte en España hasta casi entrado el siglo XIX, junto a la propia peculiaridad española del "usar y tirar" que ha venido degenerado en una falta de "cultura del mueble" a nivel general.

El perfil del comprador de mueble en España se define dentro de unos parámetros de adquisiciones para uso y decoración. En este sentido es poco habitual que un cliente español puje en una subasta por encima de los doce mil euros por una pieza de mobiliario, y de manera genérica se puede afirmar que en las subastas españolas se considera excepcional que un mueble se remate por encima de los treinta mil. Esto repercute de manera indudable en el mercado. El hecho de que existan escasos coleccionistas metódicos que creen y desarrollen su colección en un campo concreto tiene como consecuencia lógica que los marchantes tampoco se especialicen,

${ }^{24}$ Entre las más destacadas están las de Alba y Sueca. 
resultando un sector bastante heterogéneo, en muchos aspectos, y que adolece por lo general de conocimiento especializado.

Las fundaciones culturales por su implicación en el coleccionismo de arte juegan un papel importante como estimuladores del mercado, sin embargo tampoco éstas se han ocupado especialmente del mobiliario, dedicadas en su mayoría a la pintura. Destaca por su colección de muebles el Banco Central Hispano, actualmente colección Santander. Casos excepcionales son los de iniciativa particular, como el del recién inaugurado Museo del Modernismo Catalán, que cuenta con una representación exponencial de los principales mueblistas catalanes de la época a la que se circunscribe la colección.

Compradores habituales son también los comerciantes y anticuarios extranjeros, que encuentran entre las piezas que aparecen en el mercado nacional, principalmente en pintura antigua y muebles, bajos precios a los que sacar altos rendimientos en sus países de origen ${ }^{25}$. También los anticuarios españoles son compradores habituales, y además suministradores de piezas, ya que ven en esta práctica un manera fácil y rápida de dar salida a obras que han pasado años sin encontrar comprador, y que en muchas ocasiones ocupan un importante espacio físico en su tienda o galería. En este sentido los precios de las subastas han sido vistos como precios al por mayor, enfocados principalmente a los propios anticuarios (Frey 2000: 159).

A finales del siglo XIX los museos e instituciones europeas comienzan a comprar en subastas rivalizando con los coleccionistas privados. En España, superado el consabido retraso temporal con respecto al continente, el estado se ha perfilado en los últimos años como el gran comprador en subastas de arte, enriqueciendo y completando las colecciones estatales con importantes piezas, satisfaciendo así en parte el mandato establecido en el artículo 46 de la Constitución Española (Tabla 4). En el periodo comprendido entre 2004 y 2006 el Estado adquirió 1.800 obras de arte para los museos públicos, lo que supuso una inversión directa de 19 millones de euros, al margen de los pagos por dación. La Administración ${ }^{26}$ distingue diferentes

\footnotetext{
${ }^{25}$ De entre los muchos ejemplos nos ha parecido interesante el de un mueble francés sacado a la venta en 1999 por Castellana 150, en Madrid. Se trataba de un secréteaire a abattant Luis VI, rara pieza que atrajo el interés de marchates internacionales. Las pujas se elevaron de los 3 millones de pesetas en los que se estableció la salida, a 32 millones. Fue adquirido por un grupo de reconocidos marchantes Parísinos, entre los que figuraban Nicolas Jugel, Jean Marie Rossi y Maurice Segoura. Presentaba un complejo trabajo de marquetería que, en opinión de los compradores, seguía una pintura de Pierre Antoine Demarchy, del palacio de la Moneda en París. El Periódico del Arte, 18 de enero de 1999: 38.

${ }^{26}$ Amén de la Administración central, hay que tener cada vez más en cuenta el importante papel de las Administraciones Autonómicas que se vienen manifestando como destacadas compradoras del sector.
} 
formas de adquirir obras de arte, ya sea por oferta de venta directa; por oferta de venta directa irrevocable (es decir, aquellas originadas por solicitudes de exportación - tanto definitivas como temporales- con posibilidad de venta); en pago por dación de impuestos o por compra en subastas, en las de ámbito nacional ejerciendo su derecho de tanteo, mientras que en las internacionales limitándose a actuar como un cliente más. Aquellas obras adquiridas en subasta responden a propuestas de compra emitidas por la Junta de Calificación, Valoración y Exportación de Bienes del Patrimonio Histórico Español, órgano consultivo dependiente de la Dirección General de Bellas Artes y Bienes Culturales cuyas decisiones de compra determinan irremediablemente el devenir del mercado artístico nacional.

En el apartado de mobiliario el museo estatal que más ha visto aumentar sus colecciones, gracias a las compras del Estado, ha sido lógicamente el Museo Nacional de Artes Decorativas. Destacadas piezas de mobiliario han ido a completar sus fondos, ejerciendo un importante papel en la difusión y el conocimiento del mueble español.

La compra de obras por la Administración y la incorporación de estas a las colecciones públicas lleva consigo la retirada definitiva de estas piezas de los circuitos comerciales, esto tiene una consecuencia lógica que deriva no ya en una escasez de obras en circulación, pero sí cuantitativamente en una menor calidad de las mismas, de modo que cada vez resulta más complejo encontrar en el comercio piezas de calidad de determinados periodos, especialmente de "Alta Época".

\section{BIBLIOGRAFÍA CITADA}

Aguiló Alonso, M.P. 1993. El mueble en España. Siglos XVI y XVII. Madrid: CSIC y Antiqvaria. Armañanzas, E., 1993. El color del dinero. El boom de las subastas de arte, acontecimiento cultural en prensa. Bilbao: Rekargi.

Barraca, P. 2008. "El mercado del arte y la política de adquisiciones públicas", en C. Prado Román (coord.), La inversión en bienes de colección: 61-78. Madrid: Universidad Rey Juan Carlos.

Blanco A. y C. Mercado 2008. "Perspectiva de los expositores en el sector de las ferias de arte”, en C. Prado Román (coord.), La inversión en bienes de colección: 136-151. Madrid: Universidad Rey Juan Carlos.

Castedo Moya, J. 1974. Cinco años de subastas en Durán en España, 1969-1974. Madrid: Ibérico Europeo Ediciones.

Castellanos Ruiz, C. 2006 "Breves nociones sobre mobiliario español del siglo XVII", en El moble del segle XVII a Catalunya $i$ la seva relació amb altres centres europeus. Barcelona: Associació per a l'estudi del moble.

Cruz Valdovinos, J. M. 2006. "La Junta de Calificación, Valoración y Exportación de Bienes del Patrimonio Histórico Español (historiadores y estetas: ¡bajad del limbo y hablemos de dinero!)", en La multiculturidad en las Artes y la Arquitectura: 85-94 Con- 
ferencia de clausura, XVI Congreso nacional de Historia del Arte, Las Palmas de Gran Canaria.

Faraldo, R. 1971. "La necesidad de las subastas". Diario Ya, 7 de junio: 34.

Frey, B. 2000. La economía del arte. Barcelona: La Caixa.

García Osuna, C. 2006. "El mercado con techo de cristal". El Cultural. 7 de diciembre de 2006 (El Cultural Electrónico).

García Osuna, V. 2006. "El mercado del arte español". El Valor del Arte, diciembre: 7680 .

García Morcillo, M. 2005. La venta por subasta en el mundo romano: la esfera privada. Barcelona: Universidad de Barcelona.

Gaspar de Lera, S. 2005. La venta en subasta de obras de arte y otros objetos de valor, Cizur Menor: Aranzadi.

G. Maroto, M. A. 1977. "El fascinante mundo de las subastas". Bellas Artes 58: 61-64.

Iribas, A. 1998. "Entrevista con José de Paz sobre coleccionismo, mercado y subastas". Cuadernos Hispanoamericanos 572: 47-60.

Logroño, M. 1974. "Feriarte: Un Rastro de lujo". Blanco y Negro 7 de diciembre: 93-06.

López J. 2005. "Muebles realmente valiosos". Antiquaria 236: 48-68.

Mateos P. 2000. "El mejor año en la historia de las subastas en España". Arte y Subastas febrero: $28-34$.

Marín-Medina, J. 2008. "TEFAF Maastrich. Nada que ver con nada del Mundo". Tendencias del Mercado del Arte marzo: 5-8.

Monasterio, I. 1999. "Fuera de nuestras fronteras". El Periódico del Arte, suplemento al n. $\stackrel{2}{27:} 11$.

Moya Valgañón, J. G. 1990. "Un siglo de Historiografía del mueble español", en El Mueble Español. Estrado y Dormitorio. Madrid: Comunidad de Madrid.

Pérez Zúñiga, J. 1891. “iGran Almoneda!”. Blanco y Negro 12 de julio: 12.

Portús J. 1996. Mercado de Arte y coleccionismo en España (1980-1995): 13-65. Madrid: Cuadernos ICO.

Reyero, C. 2009. "El valor del precio. Tasación y compraventa de pinturas en el Madrid isabelino (1850-1868)", en Comerç, Exportació, Falsificació d'objectes d'art, e-art documents, Departamento de Historia del Arte. Barcelona: Universidad de Barcelona.

Rodríguez Bernis, S. 2006. Diccionario de Mobiliario, Madrid: Ministerio de Cultura.

Suffield, L. 1999. "Christie's innova en Mallorca". El Periódico del Arte 24, julio: 44.

Thompson, D. 2009. El tiburón de los 12 millones de dólares. La curiosa economía del arte contemporáneo y las casas de subastas. Barcelona: Ariel.

Vico Belmonte, A. 2008. "El mercado de las subastas de arte y el coleccionismo: desde sus orígenes hasta la actualidad", en C. Prado Román (coord.), La inversión en bienes de colección: 1-23. Madrid: Universidad Rey Juan Carlos.

Viloria, E. 2006. "Los valores de la obra de arte", consultado el 2011-04-04 en http:// www.analitica.com/va/arte/documentos/2994947.asp.

Fecha de recepción: 4 de diciembre de 2008

Fecha de aceptación: 5 de marzo de 2009

RDTP, vol. LXVI, n. ${ }^{\circ}$ 1, pp. 197-228, enero-junio 2011, ISSN: 0034-7981, eISSN: 1988-8457, doi: 10.3989/rdtp.2011.08 